\title{
De barmhartige Samaritaan in het Europees privaatrecht : over de gevaren van beginselen zonder een programma en een programma voor de toekomst $=$ The good samaritan in European private law: on the perils of principles without a programme and a programme for the future
}

Citation for published version (APA):

Smits, J. M. (2000). De barmhartige Samaritaan in het Europees privaatrecht : over de gevaren van beginselen zonder een programma en een programma voor de toekomst = The good samaritan in European private law: on the perils of principles without a programme and a programme for the future. Kluwer. https://doi.org/10.26481/spe.20000519js

Document status and date:

Published: 19/05/2000

DOI:

10.26481/spe.20000519js

Document Version:

Accepted author manuscript (Peer reviewed / editorial board version)

Please check the document version of this publication:

- A submitted manuscript is the version of the article upon submission and before peer-review. There can be important differences between the submitted version and the official published version of record.

People interested in the research are advised to contact the author for the final version of the publication, or visit the DOI to the publisher's website.

- The final author version and the galley proof are versions of the publication after peer review.

- The final published version features the final layout of the paper including the volume, issue and page numbers.

Link to publication

\section{General rights}

Copyright and moral rights for the publications made accessible in the public portal are retained by the authors and/or other copyright owners and it is a condition of accessing publications that users recognise and abide by the legal requirements associated with these rights.

- Users may download and print one copy of any publication from the public portal for the purpose of private study or research. - You may not further distribute the material or use it for any profit-making activity or commercial gain

- You may freely distribute the URL identifying the publication in the public portal.

If the publication is distributed under the terms of Article $25 \mathrm{fa}$ of the Dutch Copyright Act, indicated by the "Taverne" license above, please follow below link for the End User Agreement:

www.umlib.nl/taverne-license

Take down policy

If you believe that this document breaches copyright please contact us at:

repository@maastrichtuniversity.nl

providing details and we will investigate your claim. 
Dit is de letterlijke tekst van de inaugurele rede die op vrijdag 19 mei 2000 werd uitgesproken bij de aanvaarding van het ambt van hoogleraar in het recht, in het bijzonder het Europees privaatrecht aan de Universiteit Maastricht. Een uitgebreide en Engelstalige versie van deze rede verscheen bij Kluwer Deventer (ISBN 90-268-3630-9).

De barmhartige Samaritaan in het Europees privaatrecht; over de gevaren van beginselen zonder programma en een programma voor de toekomst

J.M. Smits

MIJNHEER DE RECTOR MAGNIFICUS, ZEER GEACHTE AANWEZIGEN,

Bij aanvang van deze rede, wil ik u graag terugvoeren naar de avond van 14 september 1984. Het is tegen middernacht en pikdonker. De locatie is Engeland, meer specifiek de Island Bohemian Club, gelegen op een eiland in de rivier de Thames, ergens tussen Londen en Reading. Het weer is die avond stormachtig en een van de leden van de club ziet - ongetwijfeld tot zijn stomme verbazing - op de rivier een grote passagiersboot voorbij komen. Kennelijk is deze boot losgeslagen en onbemand. De stroom dreigt de boot mee te voeren, eerst naar stroomafwaarts aangemeerde plezierboten en later naar de Reading Bridge. Actie lijkt geboden. Niet alleen boten en brug dreigen te worden beschadigd, maar óók de daarop aanwezige mensen lopen gevaar. Een vijftal members van de Bohemian Club springt in een bij het eiland aangemeerde veerboot en na enkele pogingen lukt het om iemand aan boord van de Goring (de naam van de losgeslagen boot) te krijgen, de boot weer af te meren en schade en letsel te voorkomen.

'All is well that ends well', zo zal een aantal van u thans denken. Maar dan heeft u toch buiten de juristen gerekend! Dit voorval zou een juridisch staartje krijgen dat een goed inzicht biedt in datgene wat ik vandaag aan de orde wil stellen. De vijf Barmhartige Samaritanen want dat zijn de leden van de club natuurlijk - wendden zich tot de Engelse rechter en vroegen hem om een beloning voor hun heldhaftig gedrag, een beloning te betalen door de eigenaar van de Goring. Hun redenering was simpel: zonder hun ingrijpen zou hoogstwaarschijnlijk schade zijn ontstaan aan zowel andere boten, aan de brug als aan de Goring zelf. Ook dreigde letselschade voor de op brug en boten aanwezige personen. $\mathrm{Nu}$ zij die schade hebben voorkomen, hebben zij - althans zo beweerden de vijf leden van de club - recht op een beloning. Het is met deze cliffhanger dat ik $\mathrm{u}$ thans even achterlaat.

Dames en heren, wie is benoemd op een leerstoel Europees privaatrecht verkeert in een gelukkige positie. De wetenschap van het Europees privaatrecht staat nog zeer in de kinderschoenen, zozeer zelfs dat haar beoefenaren kunnen worden vergeleken met de cartografen van vroeger. Deze kaartenmakers waren zeker van de kustlijnen van nieuw ontdekte continenten, maar zij hadden geen idee hoe het binnenland er uitzag of hoe dat moest worden bereisd, met boten, met kapmessen of op een andere manier. Over inhoud en methode van het Europees privaatrecht bestaat nog eenzelfde onzekerheid. Wij weten enkel dat er zoiets is als het Europees privaatrecht, maar hoe de terra incognita van dat rechtsgebied in te vullen, is allerminst duidelijk. Dat is natuurlijk een benijdenswaardige positie voor elke wetenschapper, maar meer nog voor een beoefenaar van het burgerlijk recht. Die heeft zich - althans in continentaal Europa - de afgelopen 200 jaar immers vooral bezig gehouden met het 
vervaardigen en interpreteren van nationale wetboeken. Thans kan de privatist zijn blikveld op ongekende wijze vergroten. Ik ben zo gelukkig om vandaag in het openbaar een leerstoel te aanvaarden die zich richt op een bijdrage aan dit fascinerende debat over het wat en hoe van het Europees privaatrecht. Vanmiddag beoog ik om u iets te laten zien van mijn visie op dat debat. En ik doe dat door de casus van de barmhartige Samaritaan als uitgangspunt te nemen. Aan de hand van die casus laat ik u ook zien wat het is dat mij drijft om onderzoek te doen naar en onderwijs te geven in dit fascinerende vakgebied.

Ik gaf u zojuist het pittoreske voorbeeld van de Goring, berecht door de Engelse House of Lords. Meer actueel en minder pittoresk is een huidige discussie in Nederland. Ik doel op de discussie over zinloos geweld. Enige maanden geleden las ik in de krant dat de gemeente Dordrecht overweegt om het ingrijpen in een situatie van zinloos geweld te bevorderen door wie zonder gevaar voor zichzelf kan ingrijpen, een beloning te geven. Kennelijk is de gemeente zich onbewust van het feit dat in Nederland reeds lang rechtsregels bestaan die soms zelfs tot ingrijpen verplichten -zoals zo dadelijk nog zal blijken. Vaak wordt de problematiek van de barmhartige Samaritaan toegelicht aan de hand van nog een ander voorbeeld. Stel dat U ziet hoe een jonge vrouw dreigt te verdrinken. $U$ bent een geoefend zwemmer en $u$ zou in staat zijn om de vrouw te redden door in het water te springen. Ook deze casus roept de vraag op of $u$ daartoe verplicht bent. Meer abstract is de vraag dan: is er een algemene plicht om mensen die in nood verkeren te redden? Vertaald naar de Goring: waren de vijf leden van de club ook verplicht om in te grijpen? Het is die vraag die ik vandaag met $\mathrm{u}$ wil bespreken. In elk Westers rechtsstelsel is de vraag bekend. Dat komt ongetwijfeld door de Bijbelse oorsprong van de casus van de Barmhartige Samaritaan, beschreven in het boek Lucas. Het zijn dit soort universele casus waar de Europese privatist iets mee kan. Zij stellen hem immers in staat om de diverse nationale oplossingen voor eenzelfde geval op zinvolle wijze met elkaar te vergelijken.

Ik wil $\mathrm{u}$ voorstellen om die vergelijking inzake de plicht tot hulpverlening eens te maken. Ik heb het dan over mensen zoals u en ik, niet over instanties als de politie of de brandweer en evenmin over de arts. Zij zijn soms op grond van publieke taak of overeenkomst verplicht om anderen te helpen. Over de hulpverleningsplicht van de gewone burger vinden wij in Europa nu zowel strafrechtelijke als civielrechtelijke regels. Alle 13 lidstaten van de Europese Unie die op het continent zijn gelegen hebben een strafwetboek en behalve Finland en Zweden hebben zij daarin alle een algemene plicht neergelegd om mensen die in nood verkeren op enigerlei wijze te helpen. Hoeden wij ons wel voor de conclusie dat daarmee strafrechtelijke uniformiteit bestaat in die elf lidstaten. Zij verschillen in bijv. wanneer precies het bieden van hulp nodig is (alleen bij levensgevaar, zoals in Nederland art. 450 van het Wetboek van Strafrecht voorschrijft, of reeds bij dreigend letsel zoals in Italië en Frankrijk), in wie hulp moet verlenen (alleen ooggetuigen van het gevaar (Italië) of ook iemand die enkel ervan op de hoogte is dat iemand in gevaar verkeert (België)). Ook in waaruit de hulp moet bestaan is er diversiteit in Europa (is het bellen van de politie genoeg of moet men zelf trachten de bedreigde persoon te redden) en ten slotte verschillen ze ook in wat de sanctie is indien men niet ingrijpt (een geldboete of hechtenis van ten hoogste drie maanden - wederom Nederland - of gevangenisstraf van zelfs maximaal vijf jaar - Frankrijk). Diversiteit dus in het strafrecht van de civil law-landen.

Kijk je vervolgens naar de andere zijde van het Kanaal, naar Engeland en Ierland, dan wordt het beeld nog meer divers. In de Europese common law-landen ontbreekt een algemene strafrechtelijke plicht om mensen in nood te redden namelijk geheel. Slechts in geval van een bijzondere relatie van afhankelijkheid is die plicht er. Ouders moeten bijv. hun hulpbehoevende kinderen voeden, zoals de werkgever zijn werknemers te hulp moet komen in geval van nood op de werkplek en de verhuurder zijn huurder soms moet helpen. In Engelse handboeken is het steevast een cliff waarvan iemand dreigt af te vallen waarmee dit wordt geïllustreerd. Moet je deze persoon waarschuwen om te voorkomen dat óók hij een cliffhanger wordt (maar van een 
andere soort dan waarvan zojuist sprake was)? Welnu: de ongelukkige behoeft niet gewaarschuwd als hij dreigt af te vallen van de cliff die in eigendom toebehoort aan een ander dan de ooggetuige, wel als het diens eigen cliff is, want dan bestaat een bijzondere relatie. Kortom: belangrijke verschillen, zowel tussen de civil law-landen onderling als tussen de civil law en de common law-landen.

Vanwaar nu deze strafrechtelijke exercitie? Ben ik soms hoogleraar geworden in het Europees strafrecht? Neen. Ik ben er echter van overtuigd dat dit verschil in strafrechtelijke benadering tussen de civil law en de common law een belangrijk punt blootlegt dat ook voor het privaatrecht van groot belang is. Wie het verzuim van een plicht strafrechtelijk bedreigt, zegt daarmee eigenlijk dat dat verzuim daarmee een zaak is van de Staat en dus van ons allen. Het is - om in de talen van twee ons omringende landen te spreken - een public wrong of schending van een Staatsbürgerliche Pflicht. Wordt de vraag of een plicht bestaat om mensen in nood te redden, geheel overgelaten aan het privaatrecht, dan is dat zo omdat een dergelijke plicht dan kennelijk niet zo belangrijk wordt geacht dat het een taak van de Staat is om die af te dwingen. Thans de vraag hoe dit inzicht zijn weerslag vindt in het burgerlijk recht van de Europese lidstaten. Het privaatrecht is ten slotte waarvoor u vandaag bent gekomen - u begrijpt dat ik de receptie na afloop nu even buiten beschouwing laat.

Ik onderzocht voor $u$ het recht van Duitsland, Nederland, Frankrijk en Portugal als representatief voor de civil law-benadering en het recht van Engeland als representatief voor de common law. Hoewel detailverschillen bestaan in de civil law, is de algemene tendens er daar een van aansprakelijkheid uit onrechtmatige daad bij nalaten een persoon in gevaar te redden, ook wanneer men die persoon in het geheel niet kent. De geoefende zwemmer die zonder veel gevaar voor zichzelf de drenkeling kan redden, moet dat doen. Doet hij dat niet, dan is hij aansprakelijk. In de common law bestaat die aansprakelijkheid tegenover vreemden niet. Wanneer u in de Londense Baker Street vlak voor een aanscheurende taxi een blinde ziet oversteken, is het luid roepen van een waarschuwing voldoende om diens leven te redden. Een easy rescue heet dat in Engeland. Toch bent $\mathrm{u}-$ als $\mathrm{u}$ die easy rescue niet verricht - niet aansprakelijk. In Nederland bent $\mathrm{u}$ dat - als u tenminste zelf bij zinnen was en u zich het gevaar realiseerde - wél indien de blinde gewond raakt door de onzachte aanraking met de aanscheurende auto.

Dat het Engelse recht weinig op heeft met Barmhartige Samaritanen komt ook tot uitdrukking in de terminologie waarmee onbaatzuchtige helpers in de common law worden aangeduid. Ik wil $\mathrm{u}$ die niet onthouden. Het meest neutraal is nog de benaming volunteers, maar wat te denken van mere strangers, officious intermeddlers of zelfs interlopers? Uit die namen spreekt reeds dat iemand die uit zichzelf een vreemde gaat helpen, dat zeker mag doen, maar een juridische verplichting daartoe heeft hij niet. En hij mag - in beginsel - ook niet verwachten daarvoor enige beloning te krijgen of - indien hij gewond raakt bij zijn reddingspoging - enige schadevergoeding. Om dit korte overzicht van Europese rechtsstelsels af te sluiten, keer ik terug naar de cliffhanger waarmee ik u zojuist achterliet: de pittoreske zaak van de Goring. Na het voorafgaande verbaast het $\mathrm{u}$ vast niet dat enige juridische verplichting om in te grijpen daar niet bestond voor de leden van de Bohemian Club. De gevorderde beloning verkregen zij evenmin.

Dames en Heren. Tot nu toe hield ik mij bezig met klassieke rechtsvergelijking. Ik onderzocht verschillen en overeenkomsten tussen diverse Europese stelsels ten aanzien van de vraag of een plicht bestaat om vreemden in nood te helpen. De rechtsvergelijker pur sang is met het thans verkregen resultaat - dat overigens subtieler is dan ik hier kon schetsen - tevreden. Zo niet de beoefenaar van het Europees privaatrecht en dus evenmin deze spreker. Karakteristiek voor mijn discipline is dat deze verder gaat dan de pure rechtsvergelijking. Zij onderzoekt namelijk op kritische wijze de mogelijkheid van Europese uniformiteit. Het rechtsvergelijkend materiaal 
wordt daarbij voorondersteld. Waar de rechtsvergelijking dus primair gericht is op hoe het thans is, voegt het Europees privaatrecht een toekomstgerichte dimensie toe. Ik geloof dat dit thans te weinig wordt begrepen en dat dit tot veel verwarring aanleiding geeft. Ik schets $u$ thans de heersende benadering van het Europees privaatrecht en geef daarop vervolgens kritiek.

Wat is die heersende benadering? De meest populaire methode op weg naar uniformiteit van recht in Europa is thans het vervaardigen van beginselen, meestal Principles geheten. Zo verschenen dit jaar in de definitieve versie de Principles of European Contract Law, gemaakt door de Lando commissie. Eerder waren er beginselen van Europees trustrecht en thans wordt gewerkt aan beginselen van Europees onrechtmatige daadsrecht. Gesuggereerd is reeds om hetzelfde te doen voor familierecht en goederenrecht. Elk van deze projecten beoogt aan de Europese rechtsstelsels gemeenschappelijke beginselen te vinden met voorbijgaan aan zoveel mogelijk verschillen als redelijkerwijs mogelijk. Voor zover daarmee daadwerkelijk overeenkomsten tussen rechtsstelsels worden blootgelegd, is er uiteraard veel voor deze benadering te zeggen. Soms hebben de Principles echter een politiek doel omdat zij door de ontwerpers worden beschouwd als de voorloper van een waarlijk Europees Burgerlijk Wetboek. Begrijpelijk is dat wel: iedereen wil zich graag het statuur van een Meijers of Portalis aanmeten. Maar er zijn ook gevaren. Zo is het bijvoorbeeld zeker mogelijk om het gemeenschappelijke aan de civil law en de common law-benadering van de aansprakelijkheid van de barmhartige Samaritaan neer te leggen in één beginsel, dat dan een grote gemene deler van alle onderzochte stelsels is. Ik heb ook geprobeerd dat voor $\mathrm{u}$ te doen op mijn eigen - wellicht gebrekkige wijze. Het Europese beginsel zou bijvoorbeeld als volgt kunnen luiden. Ik lees voor:

\section{'Indien iemand zich realiseert of zich zou moeten realiseren dat hij moet ingrijpen ten behoeve van een ander die in een toestand van acuut gevaar verkeert, heeft die persoon de plicht om dat te doen in geval van bijzondere omstandigheden. Die omstandigheden bestaan met name in geval van de schending van een strafrechtelijke bepaling of in geval van een bijzondere verhouding tussen de redder en de hulpbehoevende. De aansprakelijkheid ontbreekt echter indien de helper zichzelf in gevaar zou brengen door de hulpbehoevende te hulp te schieten.'}

Dit lijkt nu een zogenaamde common core, een grote gemeenschappelijke deler van alle Europese stelsels. Ik wil vandaag echter wijzen op drie gevaren aan deze beginselenbenadering.

Het eerste gevaar is wat de antropoloog Clifford Geertz een skeletonisation of fact noemt: van het zo volle, Rubensiaanse, lichaam van het recht (vol met details en praktische wijsheid) worden vlees en bloed afgeschraapt. Wat overblijft is een skelet. Dat komt door de reductionistische speurtocht naar de grootste gemene deler en de daarmee gepaard gaande veronachtzaming van nationale details. Het is dan niet de beste regel die wordt neergelegd in de set van Principles, maar het is de regel waarover consensus kan worden bereikt, vaak een slap aftreksel van de regels uit de nationale stelsels. U kunt zeggen dat het aan mij ligt dat mijn formulering van het beginsel over de Samaritaan bloedeloos was. Maar die bloedeloosheid is er ook bij veel regels uit de bestaande Principles-projecten.

Misschien nog wel belangrijker is een tweede bezwaar tegen de principles-benadering. Ik noem dit bezwaar de erfenis van Rabel. Ernst Rabel kan worden beschouwd als de grondlegger van de functionele benadering in de rechtsvergelijking. Hij verdedigde dat indien nu maar de typisch nationaal-juridische kwalificatie van een casus wordt genegeerd en alleen gekeken wordt naar de oplossing van de zaak, de common core vanzelf zou komen bovendrijven. Van enige normatieve discussie zou dan verder kunnen worden geabstraheerd. Dit nu is precies wat in de huidige Principles-projecten gebeurt. De uniforme beginselen worden afgeleid van de regels zoals die in de nationale rechtsstelsels thans bestaan en niet van 
de waarde-oordelen, gelegen onder die regels. Dat was niet alleen zo bij mijn formulering van een algemeen beginsel voor de aansprakelijkheid van de barmhartige Samaritaan. Het is ook zo bij veel van de bestaande Principles-projecten waarbij u wellicht méér gelooft in de redactionele vaardigheden van de Drafting Committees. Dat uit de thans bestaande nationale regels het beste Europese privaatrecht van de toekomst kan worden afgeleid, kan $i k$ echter niet geloven. Ik vraag $\mathrm{u}$ om mij te willen volgen in mijn redenering - die is misschien wat abstract, maar dat is hier onvermijdelijk. Mijn redenering luidt dat nationale regels zelf vaak niet langer uiting zijn van enige wel omschreven filosofie; dat waren zij misschien ooit, maar thans toch niet meer. Dat is geen probleem in het nationale recht omdat daar een nationale rechtscultuur bestaat waarbinnen die regels moeten worden begrepen en ook worden begrepen door hen die deze toepassen. Dat de onderliggende waarde-oordelen niet aan de oppervlakte komen, is daar geen probleem voor de belangen van partijen; onbewust wordt er in de rechtscultuur toch rekening mee gehouden door de rechtstoepassers. Dat is echter anders zodra die regels worden losgekoppeld van hun nationale omgeving. Dat kan alleen succesvol zijn indien het opstellen van beginselen hand in hand gaat met het ontwikkelen van wat ik noem een programma. Zonder dat programma, een koers die het toekomstig Europees privaatrecht moet gaan, ontbreekt de uniforme mentaliteit achter de beginselen. Dat programma kan worden vervaardigd door de achterliggende waardeoordelen, gelegen achter de regels, weer tevoorschijn te halen en die opnieuw te wegen, maar dat kan ook door een geheel nieuw programma te maken op grond van argumenten die niet zijn ontleend aan de rechtsvergelijking zelf. Die argumenten kunnen ook afkomstig zijn uit andere disciplines zoals de rechtseconomie, de psychologie, de socio-biologie of - meer juridisch - uit een grondrechten-benadering van het privaatrecht.

Ik stel voor om nu te trachten de waarde-oordelen achter het al dan niet aansprakelijk houden van de Samaritaan die niet ingrijpt te onderzoeken. Wat pleit vóór een algemene juridische plicht om mensen in nood te redden? Minstens twee argumenten. Het eerste is ontleend aan de rechtseconomie en is zeer simpel. Een algemene plicht tot hulpverlening leidt namelijk tot het redden van levens. Indien dat tegen lage kosten mogelijk is (en dat is zo indien de redder zelf geen gevaar loopt - wie niet kan zwemmen hoeft niet te proberen een drenkeling te redden), is het efficiënt om dat te doen: de welvaart van de maatschappij als geheel wordt er door vergroot. Weinig lijkt meer logisch dan dit: de plicht om in te grijpen leidt tot redden van levens. Ik moet er echter op wijzen dat dit argument is ontkracht door andere rechtseconomen. De Amerikanen Landes en Posner stellen dat juist de niet-aansprakelijkheid meer efficiënt is. Zij redeneren dat potentiële redders in de eerste plaats worden gedreven door een verlangen om publiekelijk te worden erkend als altruïsten. Als er een plicht zou zijn om te redden, kan dat niet langer, zodat maar helemaal de vraag of het aantal reddingen toeneemt. De onenigheid tussen rechtseconomen is op dit punt te groot als dat men er een argument voor of tegen aansprakelijkheid van de Samaritaan aan kan ontlenen.

Een tweede argument vóór aansprakelijkheid van de niet handelende Samaritaan is belangrijker, ja zelfs van essentieel belang voor mijn betoog. Het luidt dat het recht morele normen moet reflecteren. Als de morele norm in de maatschappij is dat de voorbijganger de blinde die oversteekt voor een aanstormende auto moet toeroepen, dan is de functie van het recht om die norm in rechte af te dwingen. Hier ligt dan duidelijk een taak voor de Staat. Het is dan immers niet langer een privé-zaak van het individu of hij besluit om in te grijpen, maar dat is een publieke zaak. Ik herinner er aan dat dit ook precies de reden was voor de strafrechtelijke bedreiging van niet ingrijpen in de civil law-landen. Voor de meeste Nederlandse juristen is dit vanzelfsprekend: gepokt en gemazeld als zij zijn in het gedachtengoed van Paul Scholten en doordrongen als zij zijn van het belang van een arrest als Lindenbaum/Cohen, weten zij niet 
anders dan dat het recht er is om de publieke moraal af te dwingen. Dat geldt - zo durf ik te stellen - meer algemeen voor de landen van de civil law op het Europese continent.

Maar, geachte toehoorders, niet geldt dit in de common law! Dat het recht normen van moraal moet afdwingen, wordt daar doorgaans ontkend. Let wel: in Engeland en ook in Amerika wordt het niet roepen naar de blinde en het niet achterna springen van een drenkeling door de Olympisch kampioen zwemmen in de moraal even laakbaar geacht als in Nederland. Wie zo handelt, wordt beschouwd als een 'ruthless savage', ‘a moral monster', maar omdat moraal en recht nu eenmaal gescheiden moeten zijn, kan men daar in het recht niets mee. De straf in geval van het niet-nakomen van morele plichten wordt niet verschaft door het recht, maar - om een Amerikaanse rechter te citeren - door een hogere wet, de `stem van het geweten, dat een snellere en zekerder straf uitdeelt dan het recht ooit zou kunnen.

Dit is in de common law - en ook in het algemeen - gelijk het belangrijkste argument tegen de algemene plicht om mensen in nood te redden. Het is ook nauw verbonden met de nadruk op vrijheid en autonomie van het individu zoals die in Amerika bestaan. Zoals een Amerikaanse auteur het zegt: de opvatting van de civil law aanvaarden zou betekenen dat Big Brother comes in. En hoewel het begrip Big Brother in Nederland het afgelopen jaar een geheel eigen betekenis heeft gekregen, ga ik er van uit dat $u$ toch begrijpt wat deze auteur bedoelt.

Het zou goed kunnen dat dit verschil tussen civil law en common law ten aanzien van de incorporatie van de moraal in het recht ook een principieel verschil over de aard van rechtsregels in civil law en common law reflecteert. Dat verschil komt bij de Samaritaan aan de oppervlakte, maar mogelijk ook op meer plaatsen in het recht. Ik ben eigenlijk overtuigd van de juistheid van deze premisse. Rechtsregels zijn in de civil law veel meer een moreel kompas, een gids voor de burger. De Staat treedt daar op als opvoeder van de burger. In de common law daarentegen zijn regels er in de eerste plaats om individuele rechten te beschermen. Niet het bevorderen van het goede, maar het garanderen van vrijheid staat voorop. Waar het onderscheid nog meer van belang is en waar het vandaan komt, kan vandaag helaas niet aan de orde komen; ik maak u naar ik hoop nieuwsgierig door te verwijzen naar de schriftelijke, uitgebreide én Engelstalige versie van deze oratie die vandaag aan de meesten van u hier aanwezig verzonden is.

Ik recapituleer. Ik heb gepleit tegen het destilleren van uniforme beginselen uit puur en alleen rechtsvergelijkend materiaal. Dat is te zeer gericht op het verleden. Argumenten over hoe het recht zou moeten zijn kunnen ook aan andere, meer consistente, disciplines dan de rechtsvergelijking worden ontleend. Ten aanzien van de Samaritaan werkte ik dat zeer kort uit door de rechtseconomie te noemen. Ik had ook nog psychologische of zelfs socio-biologische argumenten kunnen noemen als eenheid-brengende disciplines. Ik heb vervolgens de belangrijkste argumenten voor en tegen de aansprakelijkheid van de barmhartige Samaritaan voor het voetlicht gebracht. Daaruit bleek van een fundamenteel verschil tussen de civil law en de common law-benadering ten aanzien van de vraag of de moraal deel moet zijn van het recht. Het is uiteindelijk die vraag (in hoeverre moet het recht de moraal afdwingen) die de civil law en de common law op dit punt verdeeld houdt. Ik erken daarbij overigens dat in Nederland en andere civil law-landen een golfbeweging kan bestaan ten aanzien van de mate waarin het recht de moraal moet afdwingen, maar dat doet niet af aan het verschillende uitgangspunt.

Eén vraag rest: als het Europees privaatrecht zich op kritische wijze bezighoudt met de mogelijkheid van uniformiteit - zoals door mij eerder aangegeven - moet thans de vraag aan de orde komen of het ook mogelijk is tot uniformiteit te komen op het vlak van de Samaritaan.Geachte toehoorders, niet voor niets koos ik deze altruïstisch handelende persoon als onderwerp van mijn rede. Op veel terreinen van het recht kan toepassing van mijn programma van nieuwe toekomstgerichte waardenafweging inderdáád tot meer uniformiteit leiden dan thans in Europa aanwezig is. Met de barmhartige Samaritaan is dit minder zeker: het is maar geheel de vraag of de thans bestaande variëteit op dit punt moet worden opgeofferd aan 
eenheid van recht. Is daar behoefte aan? Is het bijvoorbeeld erg wanneer $u$ als getuige van een dreigende verdrinking in de fontein op Trafalgar Square anders wordt behandeld dan als getuige van diezelfde dreigende verdrinkingsdood in de fontein op de Piazza Navona in Rome? Ik denk het niet. Verrassend is dat ook niet want de verschillen op dit punt zijn geen belemmering voor het functioneren van een gemeenschappelijke Europese markt. Er is geen economische reden voor harmonisering. Maar zelfs als men die uniformiteit hier zou wensen, is het ook niet mogelijk om die te bereiken. In dit soort gevallen is de moraal een waarde op zichzelf. Het recht is dan iтmиип voor harmonisatie, niet omdat het recht wordt meegeërfd met de genen, maar omdat het deel is - om de Maastrichtenaar Hofstede te citeren - van de 'mentale software' van een rechtsstelsel.

Dit soort gevallen, waarin moralen verschillen, zijn echter uitzonderlijk. Veel regels in de civil law hebben géén educatieve functie; veel in de common law heeft níet de functie van garanderen van vrijheid aan de burgers. Grote delen van het contractenrecht, het recht inzake de onrechtmatige daad en het goederenrecht kunnen beter in andere termen dan die van moraal worden begrepen. De onderliggende waarden zijn daar immers veel meer geënt op zulke uiteenlopende grootheden als efficiency, consumentenbescherming, bescherming van slachtoffers en een juiste verdeling en bescherming van eigendom. Door het wegen van deze waarden en - nogmaals - niet door de positiefrechtelijke regels als uitgangspunt te nemen, kan een consistent én uniform Europees privaatrecht daar wél ontstaan.

Ik kom toe aan het laatste deel van mijn oratie. Ik wil daarin - deels samenvattend - aangeven wat mijn uitgangspunten zijn bij mijn toekomstige beoefening van het Europees privaatrecht. Ik offreer u hierbij dus mijn geloofsartikelen, drie in getal. Het eerste onderdeel van dit 'programma voor de toekomst' verbaast u na het voorgaande vast niet: ik geloof in een interdisciplinaire benadering bij het ontwikkelen van een nieuw recht voor Europa. Niet alleen de privaatrechtelijke rechtsvergelijking, ook de rechtseconomie, de rechtstheorie, Grondrechten en zelfs antropologie en psychologie kunnen daaraan bijdragen. Interdisciplinariteit is overigens niet alleen van belang voor het Europese privaatrecht. Het heeft óók als voordeel dat een maatstaf ontstaat voor het nationale recht, dat vervolgens kan worden getoetst aan de onderzoeksresultaten die het nieuwe programma heeft opgeleverd. Aldus kijken wij op alle fronten - nationaal en Europees - vooruit naar hoe het recht zou moeten zijn.

Ook mijn tweede uitgangspunt kwam in het voorafgaande reeds aan de orde. Het grote voordeel van economische of andere niet-strikt-juridische analyse van het recht is, dat het de particulariteit van het nationale recht contrasteert met de universaliteit van die andere disciplines. Maar ik gebruikte de barmhartige Samaritaan ter illustratie van het feit dat die exercitie niet altijd geheel ten einde moet worden gevoerd. Sommige delen van het recht blijven immuun voor harmonisatie. De idee dat uniformiteit altijd superieur zou moeten zijn aan diversiteit weiger ik dus te aanvaarden. En dat diversiteit een historisch ongelukje is, waarbij de afgelopen twee eeuwen als een kort exotisch interval waarin iedere natie-staat zijn eigen recht had, moeten worden beschouwd, geloof ik evenmin. Een van de grote uitdagingen van mijn discipline is om uit te vinden welke rechtsregels wèl en welke nìet zullen overwinnen op de markt van rechtscultuur. Dat hangt af van de mate van gevoeligheid van die regels voor nationale moraal. En dat brengt mij - ten slotte - op mijn derde geloofsartikel.

Mijn derde uitgangspunt is dat ik geloof in het grote nut van kijken naar gemengde rechtsstelsels, stelsels waarin in het verleden al een mengeling van civil law en common law tot stand gebracht is. Ik denk daarbij met name aan Zuid-Afrika, aan Schotland, aan Louisiana en aan Québec. Deze gemengde stelsels laten ons zien welke regels als inherent deel worden beschouwd van de civil law en welke van de common law-moraliteit. Het recht van Louisiana en Québec tonen bijv. aan dat de aansprakelijkheid van de Barmhartige Samaritaan zeer moraalgevoelig is nu deze stelsels die aansprakelijkheid in respectievelijk een common law en een 
civil law-omgeving niet en wel kennen. Ik beoog in mijn onderzoek naar de mogelijkheid van een uniform Europees privaatrecht gebruik te maken van dit soort inzichten, overigens naast de vele andere inzichten die de gemengde stelsels ons opleveren. Ook híer ligt een fascinerend terrein braak, net zoals de gehele studie van het Europees privaatrecht een fascinerend nieuw onderzoeksterrein is. Ik hoop u dat in de afgelopen 40 minuten voldoende duidelijk te hebben gemaakt.

\section{Mijnheer de Rector, Dames en Heren,}

Aan het einde gekomen van mijn rede, spreek ik graag enkele woorden van dank. Die dank geldt in de eerste plaats de leden van het College van Bestuur van deze Universiteit. Het vertrouwen dat zij blijkens mijn benoeming op deze leerstoel in mij uitspreken, hoop ik niet te zullen beschamen. Ik dank ook diegenen die aan mijn benoeming hebben bijgedragen, in het bijzonder het Bestuur van de Faculteit der Rechtsgeleerdheid. Uw aller betrokkenheid bij de instelling van een leerstoel Europees Privaatrecht heeft mij diep geraakt. Weet dat ik mij naar beste vermogen zal inzetten voor de verdere uitbouw van die leerstoel en voor een belangrijke Maastrichtse bijdrage aan het Europees-privaatrechtelijk onderzoek en onderwijs.

Dit brengt mij bij enkele meer persoonlijke woorden.

Waarde leden van de Capaciteitsgroep Privaatrecht en van de Juridische Faculteit Maastricht. Vanaf het allereerste moment - thans drie en een half jaar geleden - dat ik werkzaam was in uw midden, heb ik mij in Maastricht thuis gevoeld. De dagelijkse contacten die ik met u onderhoud - niet enkel op wetenschappelijk vlak, maar ook in het persoonlijke - worden door mij zeer gewaardeerd. Hoewel enkelen noemen anderen tekort doet, heeft u er vast alle begrip voor dat $\mathrm{ik}$ in het bijzonder drie personen noem.

Waarde Van Maanen, Beste Gerrit, waarde De Groot, beste René. Het vervult mij met vreugde dat ik mag bijdragen aan de fraaie wijze van privaatrechtsbeoefening die u met name aan onze Faculteit in zeer goede sfeer heeft opgebouwd. Het verheugt mij dat u mij in de afgelopen jaren alle vrijheid heeft gegeven om mij verder te ontwikkelen van 'platte civilist' tot meer internationaal georiënteerd wetenschapper. Dat $u$ de wetenschap niet enkel in het OudGouvernement beoefent, maar ook daarbuiten, bijvoorbeeld op de fiets of in de biljartkamer, en mij daarin laat delen, verheugt mij al evenzeer. Ik kijk oprecht uit naar onze verdere samenwerking.

Waarde Faure, beste Michael. Ik heb grote waardering voor de wijze waarop $u$ het rechtsgeleerd onderzoek binnen onze Faculteit behartigt. Uw inzet meer in het bijzonder voor het ius commune-onderzoek binnen de gelijknamige Onderzoeksschool en voor de wijze waarop u anderen stimuleert om over de grenzen van nationaal recht en van recht in het algemeen te kijken, ervaar ik als inspirerend. Ook met u hoop ik nog lang te kunnen samen werken.

Waarde Hijma, beste Jaap. Ik mag mij uw eerste promotus noemen. Daar ben ik trots op. Wat ik tijdens mijn leerjaren in Leiden het meeste in u heb gewaardeerd, was de grote vrijheid die u mij heeft gegeven. Ik kon mijn eigen weg gaan en mij bezig houden met veel meer dan alleen het Nederlandse positieve recht. Ik ben er van overtuigd dat zonder die vrijheid die ik als promovendus van $\mathrm{u}$ kreeg, ik hier vandaag niet had gestaan. In die zin staat $\mathrm{u}$ aan de wieg van de wijze van wetenschapsbeoefening die ik voorsta. 
Lieve ouders, jullie staan letterlijk aan de wieg van mijn carrière in de wetenschap. Jullie hebben mij geleerd dat je bij alles wat je onderneemt je best moet doen, maar ook dat je niet meer kunt dan dat. Ik ben blij met die les, zoals ik blij ben dat jullie vandaag hier zijn. Beste Herman, Rob en Graziena: ik ben blij dat ook jullie vandaag aanwezig zijn. Ik weet dat jullie gedachten de afgelopen drie kwartier niet steeds waren bij wat $i k$ had te zeggen, maar ook uitgingen naar Conny. Dat zij er niet meer is, is voor ons allen nog steeds onvoorstelbaar. Haar moed, vastberadenheid en relativeringsvermogen blijven mij tot voorbeeld.

Lieve Christa, Niet veel Nederlandse geliefden ontmoeten elkaar in een land als Moldavië. Wij wel. Ik hoef je vanaf deze plaats niet te zeggen hoe blij ik ben met die ontmoeting en met wat daarop volgde. Voor mijn beoefening van het privaatrecht is jouw aanwezigheid altijd inspirerend; wat je daarnaast voor mij betekent is van dien aard dat ik het bij een gelegenheid als deze met geen mogelijkheid onder woorden kan brengen. Maar ook dat weet je gelukkig.

Dames en heren studenten. Traditioneel is het laatste woord voor u. Mijn aanstelling is grotendeels gericht op onderzoek, maar gelukkig ben $i k$ niet in staat om onderzoek van onderwijs te scheiden. In het onderwijs dat ik u geef probeer ik steeds om u niet alleen te doordringen van het grote belang van een internationale beoefening van het privaatrecht, maar óók van het feit dat $\mathrm{u}$ het privaatrecht vooral passioneel moet beoefenen. Ons vakgebied biedt daartoe alle mogelijkheid vanwege de vele dilemma's van grote wetenschappelijke én maatschappelijke waarde die het kent. Voor zover ik u vandaag niet van díe les heb kunnen overtuigen, verheug ik mij er op dat in mijn onderwijs aan u alsnog te kunnen doen.

\section{IK HEB GEZEGD}

